\title{
Probabilistic analysis of flood embankment stability: the case study of the Adige River embankment in Italy
}

\author{
Alessia Amabile ${ }^{1 *}$, Fabio De Polo ${ }^{2}$, and Alessandro Tarantino ${ }^{1}$ \\ ${ }^{1}$ Department of Civil and Environmental Engineering, University of Strathclyde, Glasgow, UK \\ ${ }^{2}$ Hydraulic Department, Civil Protection Agency, Bolzano, Italy
}

\begin{abstract}
Flooding is a worldwide phenomenon. Over the last few decades the world has experienced a rising number of devastating flood events and the trend in such natural disasters is increasing. Furthermore, escalations in both the probability and magnitude of flood hazards are expected as a result of climate change. Flood defence embankments are one of the major flood defence measures and stability assessment for these structures is therefore a very important process. Traditional deterministic approaches to stability analysis do not allow taking into account and quantifying the uncertainties in soil characterisation. For this reason they may not be sufficient to capture the failure of flood embankments. The paper presents a probabilistic approach for the stability analysis of flood embankments taking into account the probabilistic distribution of soil hydro-mechanical properties. The approach is validated against the failure case study of the Adige river embankment in Italy, by comparing the probability of failure of two sections, within and outside the failure segment respectively.
\end{abstract}

\section{Introduction}

In the current engineering practice, the common methods for designing or verifying geotechnical structures, such as dams or embankments, are mostly deterministic. This means they treat soil property values as if they were fixed, and precisely known. However the hydromechanical characterisation of soils involves uncertainties generated by the natural variability of soils and very often by the scarcity of experimental data. Common deterministic methods don't take into account uncertainties associated to variability of soil properties. A probabilistic approach, on the other hand, allows to quantify the uncertainties involved in the design process and to assess how these uncertainties affect the safety of the structure. In the context of slope stability, the result of a deterministic stability analysis is a single value of the Factor of Safety; the failure corresponds to a value of Factor of Safety lower than or equal to one. However this approach fails to give a complete description of the full range of the possible outcomes. With a probabilistic approach the result is expressed in terms of probability of failure, which corresponds to the probability of observing a Factor of Safety lower than or equal to one.

This paper aims at showing that traditional deterministic approaches may overestimate the safety of geotechnical structures. The First Order Second Moment method is used to calculate the probability of failure of a flood embankment; results are discussed and compared to a traditional deterministic stability analysis. The analysis is developed with reference to a segment of embankment along the Adige River in the North of Italy
(Fig. 1), where a failure was observed in 1981 during a flood event.

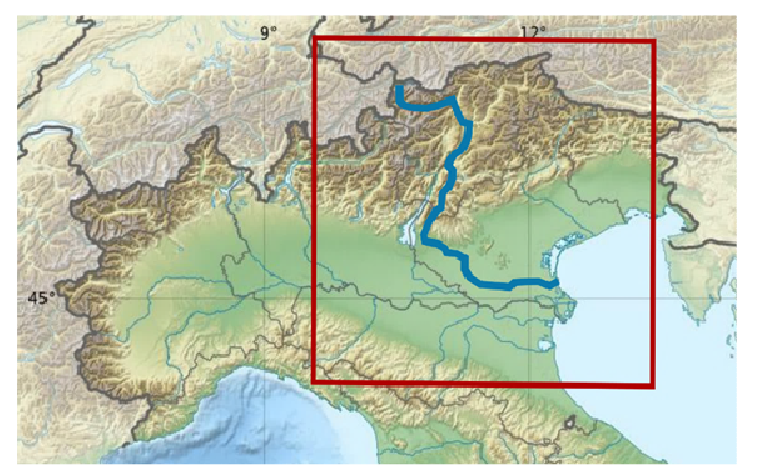

Fig. 1. Adige River in North-Eastern Italy.

\section{The case study}

The Adige River is the second longest river in Italy and it flows from the Alps through most of North Eastern Italy. Embankments were built along the Adige River at the end of the $19^{\text {th }}$ century [1]. The area examined in the present study is located near the village of San Floriano (Bolzano), where a scarp was observed along a segment of about $150 \mathrm{~m}$ during an intense flood event in 1981. Two cross-sections were examined, one located within the failure zone and the other located outside the failure zone.

\footnotetext{
Corresponding author: alessia.amabile@ strath.ac.uk
} 


\section{The hydro-mechanical model}

\subsection{Soil profile and material characterisation}

The embankment is about $8 \mathrm{~m}$ high from the riverbed and about $4 \mathrm{~m}$ high from the ground surface on the landside. The soil profile was inferred from visual inspection of borehole samples and DPH tests, and subsequently confirmed by the grain size analysis of samples collected from the identified soil layers [2]. The material that constitutes the core of the embankment is a sandy silt, while the foundation layers are made of coarse material. The geometry and soil profile of both cross-sections is shown in Fig. 2.

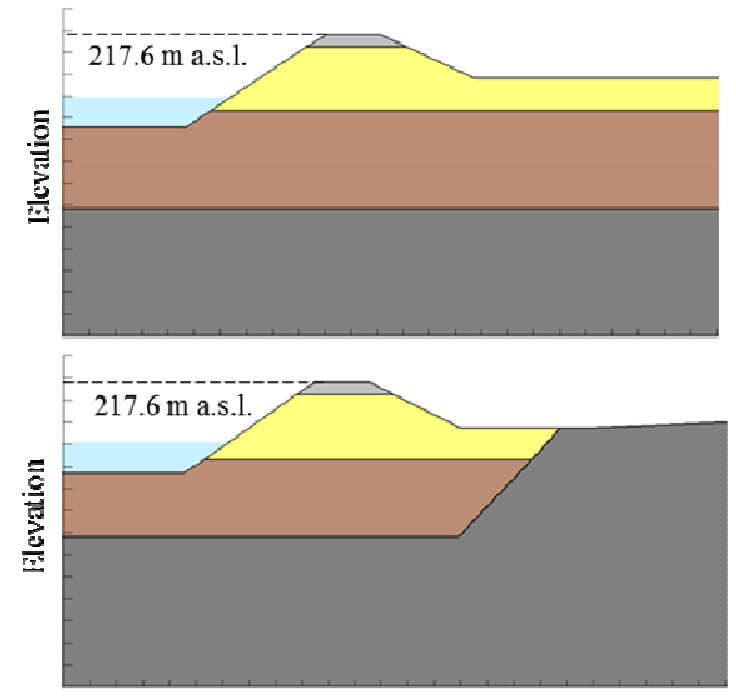

Fig. 2. Soil profile for cross sections outside the failure zone (top) and within the failure zone (bottom).

Hydro-mechanical material properties were derived from field and laboratory tests [2]. The shear strength of the embankment core material was obtained from direct shear tests, which showed a friction angle equal to $28.9^{\circ}$. The saturated hydraulic conductivity of the embankment core material and foundation material was obtained by inverse analysis based on the measurements of tensiometers and piezometers installed in the field.

The water retention curve of the embankment core material was obtained in the lab and the experimental data points were fitted with Van Genuchten model [3]. Effective saturation and water content are defined in Eq. (1) and Eq. (2) respectively:

$$
\begin{gathered}
S_{e}=\frac{1}{\left(1+(\alpha s)^{n}\right)^{m}} \\
\theta=\theta_{\text {res }}+\left(\theta_{\text {sat }}-\theta_{\text {res }}\right) S_{e}
\end{gathered}
$$

where

$$
m=1-\frac{1}{n}
$$

$s$ is the suction and $\theta_{\text {res }}$ and $\theta_{\text {sat }}$ are the residual and saturated volumetric water content respectively.

The relative hydraulic conductivity $k_{\text {rel }}$ was derived from the water retention curve using the Van Genuchten model, as expressed in Eq. (4):

$$
k_{r e l}=S_{e}^{-\lambda}\left(1-\left(1-S_{e}^{\frac{1}{m}}\right)^{m}\right)^{2}
$$

\subsection{Seepage and stability analysis}

A transient-state seepage analysis was performed in order to evaluate the distribution of pore water pressure in the embankment during the flood event in July 1981. The analysis was performed using the finite element software SEEP/W [4], which takes into account flow in unsaturated soils.

The boundary condition on the riverside is given by the time-dependent hydraulic head represented by the hydrograph recorded during the flood event (Fig. 3).

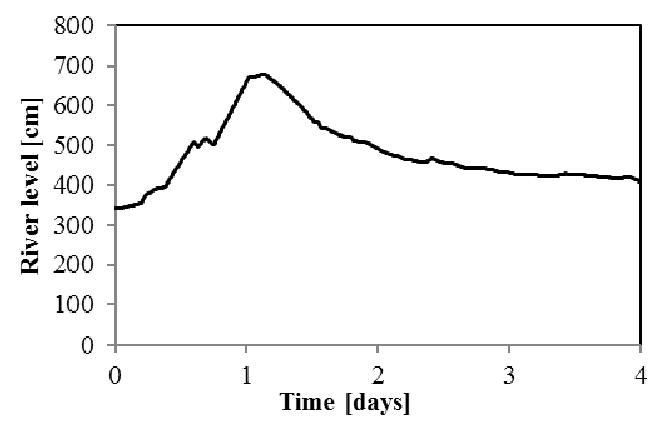

Fig. 3. Hydrograph recorded during the flood event in 1981.

In the transient-state seepage analysis the vertical boundary on the landside and the bottom boundary are modelled as impermeable boundaries; the distance of the landside vertical boundary from the toe of the embankment was chosen so that the pore-water pressure distribution in the embankment is not controlled by the boundary condition on the landside, but by the water flow determined by the boundary condition on the riverside. The vertical boundary on the riverside is also modelled as an impermeable boundary because it is located on the symmetry axis of the river, therefore no flow can occur through it. The crest of the embankment, the landside slope and the ground surface are modelled as potential seepage faces, where pressure can never exceed atmospheric pressure [2]. The initial condition for the transient-state seepage analysis was obtained from a steady-state analysis associated with a river level equal to the initial river level for the flood event.

For the stability analysis Bishop's simplified method was used [5]. The soil is assumed to have rigid-perfectly plastic behaviour, i.e. it is assumed that soil does not show any deformation before failure; the solution of the problem is based only on equilibrium equations. The software SLOPE/W [6] was used to solve the iterative procedure for the calculation of the Factor of Safety. The values of pore water pressure obtained from the software SEEP/W were used in the stability analysis to calculate the value of Factor of Safety for the entire duration of the flood event. 
The software SLOPE/W includes an unsaturated shear strength model based on the water retention curve of the material [7].

\section{Application and results}

\subsection{The deterministic analysis}

The Factor of Safety was calculated for both cross sections with a time step of three hours for the entire duration of the flood event. Results are shown in Fig. 4.

The value of the minimum Factor of Safety $\mathrm{FS}_{\text {min }}$ is equal to 1.16 for the failed section and 1.63 for the stable section. The minimum Factor of Safety $\mathrm{FS}_{\text {min }}$ corresponds to the peak of the hydrograph for the failed section and is attained a few hours after the peak for the stable section. The minimum Factor of Safety $\mathrm{FS}_{\text {min }}$ for the failed section is greater than 1 , thus leading to the conclusion that the embankment should have not failed under the flood event here examined.

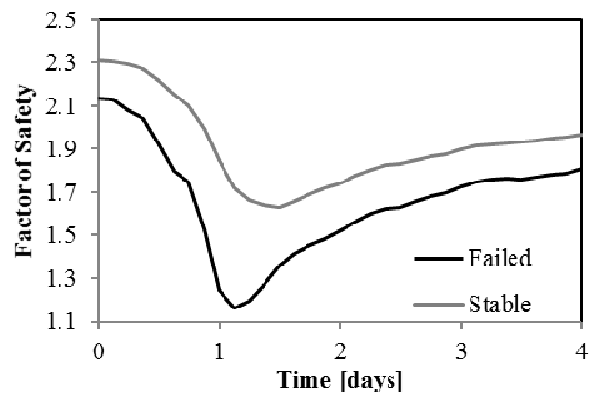

Fig. 4. Factor of Safety during the flood event in 1981.

\subsection{The probabilistic analysis}

For the probabilistic analysis the First Order Second Moment (FOSM) method has been used. The FOSM method is based on the first-order Taylor series expansion of the performance function about its mean value. It is used to calculate the first and second moment, i.e. mean and variance, of the performance function, as expressed by Eq. (5) and Eq. (6) respectively:

$$
\begin{gathered}
E[Y] \cong g\left(E\left[X_{1}\right], E\left[X_{2}\right], K, E\left[X_{n}\right]\right) \\
\sigma^{2}[Y] \cong \sum_{1}^{n}\left(\frac{\partial g}{\partial X_{i}}\right)^{2} \sigma^{2}\left[X_{i}\right]
\end{gathered}
$$

where $Y=g\left[X_{1}, X_{2}, \ldots, X_{n}\right]$ is the performance function and $X_{1}, \ldots, X_{n}$ are the input random variables. If input variables are not independent, correlation has to be taken into account for the calculation of the variance $\sigma^{2}[Y]$.

The analytical calculation of the partial derivatives in Eq. (6) may be complex for many geotechnical problems; they can be estimated numerically by computing the performance function at two different points. A common practice [8] is to select two points over a range of plus and minus one standard deviation with respect to the mean value of the random variable $X_{i}$, as shown in Eq. (7), in order to cover a range of likely values for the performance function:

$$
\frac{\partial g}{\partial X_{i}}=\frac{g\left(\mu\left[X_{i}\right]+\sigma\left[X_{i}\right]\right)-g\left(\mu\left[X_{i}\right]-\sigma\left[X_{i}\right]\right)}{2 \Delta X_{i}}
$$

In the context of slope stability, the performance function is represented by the Factor of Safety. In order to apply the FOSM method all the input variables have to be characterised by a mean and standard deviation.

Four material properties have been identified as critical parameters for the stability of the embankment, i.e. the friction angle, the saturated hydraulic conductivity and the $\alpha$ and $n$ parameters in the Van Genuchten model for water retention curve. For these parameters the experimental values have been assumed as mean values, while the standard deviation has been estimated from coefficients of variations $\mathrm{CoV}$ for similar soil types published in the literature [9]. No correlation has been assumed between the variables. A summary is reported in Table 1.

Table 1. Material properties.

\begin{tabular}{|c|c|c|}
\hline Variable & Value & CoV [\%] \\
\hline$\varphi^{\prime}\left[{ }^{0}\right]$ & 28.9 & 6 \\
\hline $\mathrm{k}_{\text {sat }}[\mathrm{m} / \mathrm{s}]$ & $2 \mathrm{E}-6$ & 90 \\
\hline$\alpha[1 / \mathrm{kPa}]$ & 0.07 & 60 \\
\hline $\mathrm{n}$ & 1.438 & 9 \\
\hline$\theta_{\text {sat }}$ & 0.42 & 0 \\
\hline$\theta_{\text {res }}$ & 0.008 & 0 \\
\hline
\end{tabular}

For each of the four independent input variables $(\varphi$, $\left.k_{s a t}, \alpha, n\right)$ the Factor of Safety was calculated in three points, one corresponding to the mean value $\mu$ and two corresponding to the mean value plus and minus the standard deviation $(\mu+\sigma, \mu-\sigma)$. This corresponds to running a total of $2 m+1=9$ simulations, where $m$ is the number of input variables. Only the critical failure surface returned within the deterministic analysis was analysed in all simulations. The values of minimum Factor of Safety obtained for both sections in all 9 simulations are reported in Table 2. The first simulation corresponds to the routine deterministic analysis shown in the previous section and is used to calculate the mean value of the Factor of Safety starting from the mean values of the input variables, as shown in Eq. (7). The remaining $2 m$ simulations are run to calculate the variance of the Factor of Safety and take into account the variance of the input variables, as shown in Eq. (8) [10].

$$
\begin{gathered}
E\left[F S_{\text {min }}\right] \cong F S_{\text {min }}\left(E\left[\varphi^{\prime}\right], E\left[k_{\text {sat }}\right], E[n], E[\alpha]\right) \\
\sigma^{2}\left[F S_{m}\right] \cong+\left(\frac{\partial F S_{m}}{\partial k_{\text {sat }}}\right)^{2} \sigma^{2}\left[k_{\text {sat }}\right]+\left(\frac{\partial F S_{m}}{\partial \varphi^{\prime}}\right)^{2} \sigma^{2}\left[\varphi^{\prime}\right] \\
+\left(\frac{\partial F S_{m}}{\partial n}\right)^{2} \sigma^{2}[n]+\left(\frac{\partial F S_{m}}{\partial \alpha}\right)^{2} \sigma^{2}[\alpha]
\end{gathered}
$$


In order to calculate the probability of failure, a probability distribution needs to be assumed for the Factor of Safety. A LogNormal distribution has been assumed here, as recommended by previous studies in the literature [9]. The probability of failure is equal to $11.3 \%$ for the failed section and $0.1 \%$ for the stable section. The difference in probability of failure between the two sections is of two orders of magnitude, thus explaining why one of them was stable and the other failed during the same flood event.

Table 2. Minimum Factor of Safety for all simulations in FOSM method.

\begin{tabular}{|cc|cc|}
\hline \multicolumn{2}{|c|}{ Simulation } & Failed & Stable \\
\hline 1 & mean & 1.160 & 1.631 \\
2 & $\varphi^{(\mu+\sigma)}$ & 1.242 & 1.746 \\
3 & $\varphi^{(\mu-\sigma)}$ & 1.099 & 1.546 \\
4 & $\mathrm{k}_{\text {sat }}{ }^{(\mu+\sigma)}$ & 1.126 & 1.523 \\
5 & $\mathrm{k}_{\text {sat }}{ }^{(\mu-\sigma)}$ & 1.347 & 1.888 \\
6 & $\mathrm{n}^{(\mu+\sigma)}$ & 1.165 & 1.686 \\
7 & $\mathrm{n}^{(\mu-\sigma)}$ & 1.169 & 1.638 \\
8 & $\alpha^{(\mu+\sigma)}$ & 1.187 & 1.745 \\
9 & $\alpha^{(\mu-\sigma)}$ & 1.118 & 1.486 \\
\hline
\end{tabular}

One of the major advantages of FOSM method is that the terms $w\left[X_{i}\right]$ (Eq. (9)) provide an immediate quantitative assessment of the influence of the variability of each input variable on the variance of the Factor of Safety. The results for both sections are reported in Table 3 .

$$
w\left[X_{i}\right]=\frac{\left(\frac{\partial F S_{m}}{\partial X_{1}}\right)^{2} \sigma^{2}\left[X_{i}\right]}{\sigma^{2}\left[F S_{m}\right]}
$$

Table 3. Relative contribution of each input variable to the variability of the Factor of Safety.

\begin{tabular}{|c|cc|}
\cline { 2 - 3 } \multicolumn{1}{c|}{} & Failed & Stable \\
\hline $\mathrm{w}\left[\mathrm{k}_{\text {sat }}\right]$ & $66 \%$ & $55 \%$ \\
$\mathrm{w}\left[\varphi^{\prime}\right]$ & $28 \%$ & $16 \%$ \\
$\mathrm{w}[\mathrm{n}]$ & $0 \%$ & $1 \%$ \\
$\mathrm{w}[\alpha]$ & $6 \%$ & $28 \%$ \\
\hline
\end{tabular}

The partial derivative in Eq. (9) represents how much the Factor of Safety is affected by the change of a single variable, while the variance $\sigma^{2}\left[X_{i}\right]$ represents the uncertainty in the assessment of the variable itself. This means that each variable can contribute significantly to the uncertainty in the Factor of Safety in two cases: if the Factor of Safety is strongly dependent on said variable (i.e. the derivative in the term is large) or if there is great uncertainty in the assessment of said variable (i.e. the term $\sigma^{2}\left[X_{i}\right]$ is large). While the derivative depends on the physical process and the model used to describe it, the term $\sigma^{2}\left[X_{i}\right]$ can be reduced by decreasing the uncertainty in the assessment of the variable. This can provide a useful tool for managing investment in geotechnical engineering practice, for example by focusing resources in the investigation of the more relevant soil property, which in this case is represented by the saturated hydraulic conductivity. On the other hand, the slope of the water retention curve appears to have little influence on the variability of the Factor of Safety, with the term $w[n]$ being equal to 0 and $1 \%$ for the failed and stable sections respectively.

\section{Conclusions}

For the stability analysis of flood embankments it is important to take into account uncertainties in the hydromechanical properties of materials. Traditional deterministic approaches to stability analysis do not allow taking into account and quantifying the uncertainties in soil characterisation. For this reason they may not be sufficient to capture the failure of flood embankments. This has been proved by analyzing a case study of a failure of a flood embankment on the Adige River observed during a flood event in 1981. Two cross sections were examined, one within the failure zone and the other outside. Although in the deterministic analysis a difference was observed between the Factor of Safety values calculated for the two sections, in both cases the minimum Factor of Safety is greater than one for the entire duration of the flood event. This implies that the embankment should not have failed in 1981.

The results of the probabilistic analysis have shown a probability of failure equal to $11.3 \%$ for the failed section and $0.1 \%$ for the stable section. In the context of risk management there are no clear-cut prescriptions for acceptable or unacceptable probabilities of failure, being the threshold also dependent on different aspects such as number of fatalities or economic damage. However, $10 \%$ is usually considered as an upper bound for acceptable probability of failure, for the case when consequences of failure are not severe [11]. Results in this paper show that the variability of material properties and especially of the hydraulic conductivity has a significant effect on the safety of the embankment and it cannot be neglected.

Compared to other probabilistic approaches, the application of the FOSM method does not require much more time and computational effort than a traditional deterministic analysis. The time and number of simulations required to achieve a sufficiently accurate estimate of the probability of failure are manageable with any available commercial software. The FOSM method is therefore a suitable and affordable approach to assess the stability of flood embankments in probabilistic terms for routine applications in geotechnical engineering.

\section{Acknowledgements}

The authors wish to acknowledge the support of the European Commission via the Marie Curie IRSES project GREAT 'Geotechnical and geological Responses to climate change: Exchanging Approaches and Technologies on a world-wide scale' (FP7-PEOPLE-2013-IRSES-612665). The authors also wish to acknowledge the support of the Autonomous Province of Bolzano, Italy. 


\section{References}

1. K. Werth, Geschichte der Etsch: zwischen Meran und San Michele. Flussregulierung, Trocken-legung der Möser, Hochwasserschutz (Tappeiner, 2003)

2. A. Amabile, A. Pozzato, A. Tarantino, Instability of flood embankments due to pore water pressure build-up at the toe: lesson learned from the Adige River case study, Can. Geotech. J. (accepted, in press)

3. M. Van Genuchten, Soil Sci. Soc. Am. J., 44, 892898 (1980)

4. GEO-SLOPE, Seepage Modeling with SEEP/W (GEO-SLOPE International, Ltd, 2004)

5. A. Bishop, Géotechnique, 5(1), 7-17 (1955)

6. GEO-SLOPE, Stability Modeling with SLOPE/W (GEO-SLOPE International, Ltd, 2004)

7. S. Vanapalli, D. Fredlund, D. Pufahl, A. Clifton, Can. Geotech. J., 33, 379-392 (1996)

8. T. Wolff, Geotechnical Reliability of Dam and Levee Embankments (U.S. Army Corps of Engineers, 2004)

9. J. Duncan, J. Geotech. Geoenviron. Eng., 126(4), 307-316 (2000)

10. A. Amabile, M. P. Cordão-Neto, A. Pozzato, A. Tarantino, An accessible approach to assess the probability of failure of flood embankments (in preparation)

11. K. Phoon, Reliability-Based Design in Geotechnical Engineering. Computations and Applications (Taylor \& Francis, 2008) 